\title{
Benefits of the EduPlan/EX software platform in managing teaching processes
}

\author{
Gloria Vickov \\ Department of Teacher Education \\ Faculty of Humanities and Social Sciences \\ University of Split, Croatia \\ Correspondence: \\ gvickov@ffst.hr \\ Tel.:/Fax.: + 38521541914
}

Received: 29 July 2016; Accepted: 30 July 2016

Key words: Management of teaching processes Medical school $\bullet$ EduPlan/EX software.

In their paper entitled Management of teaching processes using Share point platform: A case study from the University of Split School of Medicine Sapunar, Grković, Lukšić and Marušić draw our attention to the development of a software tool which provides a systematic solution to the problem of budget allocation to medical schools in Croatia and, in general, a reliable aid in managing teaching processes (1).

As reported by the authors, according to the experience with the Medical School in Split, the EduPlan/EX software successfully deals with systematic determining the teaching load which is the main element for new employments in Croatian academic community. This makes the teaching load one of the main factors in determining budget allocation. Taking into consideration the fact that currently there are no clear budget al- location principles and that the documents, which serve as a basis for determining the schools' budgets, are rather scarce (1), one easily becomes aware of the importance of having a software platform that encompasses all information relevant for automatic generation of teaching loads. However, determination of the teaching load is not the only benefit of the EduPlan/EX software platform. Let's have a closer look at other advantages of this application.

The system involves the scheduling functionality aimed at creating precise timetable several months before the start of the academic year. Not only does this functionality allow planning and scheduling of teaching and extracurricular activities, but it also provides online access to timetable (of all teaching/space allocation modalities) and allows avoiding conflict in classroom booking. As the planning includes entry of all elements of the teaching based on one teaching hour as the core unit comprising course, topic, time, teaching room, teacher, type of the teaching and the student group, the platform offers real time availability information for all teaching locations. This then allows resource sharing and the efficient management of teaching resources. The planning and scheduling functionality also removed the initial discrepancies between the syllabi of several subjects and their plans for the current academic year, as well as the 
discrepancies between the teaching plans and data entered in the program. This again allowed further synchronizing all the relevant data to the satisfactory level. EduPlan/ EX software also allows identifying departments with high teaching load of external experts and distributing that teaching load to employed faculty, which results in reducing the costs of contract teachers.

It is exactly the aspect of external teachers that additionally illustrates the usability and efficiency of this Share point platform. It provides automatic generation of payment contracts for numerous external experts, which considerably reduces exhausting administrative work of several School's offices. Not to mention that such a reduction of administrative work has been, of course, achieved with respect to all the faculty members. The system allows automatic processing of all the relevant data related to the faculty members' teaching workload, with numerous variations of their contracts, their academic status, planned and completed teaching hours. Due to its functionality related to generation of the reports on planned and delivered teaching activities, the platform provides an easily operated IT framework for conducting analyses which could result in information necessary for making adjustments, corrections and improvements in the teaching process.

Finally, EduPlan/EX software keeps track of the changes in the planned teaching activities that occur due to the engagement of different teachers. These changes, which seem to be relatively frequent and difficult to manage on time, present an area within which the authors announce further im- provements of the currently used version of the program.

Having in mind the above stated benefits of the EduPlan/EX software one can hardly be surprised by the fact that this program was proclaimed a business solution with highest business value at the Windays 2012 conference. The University of Split School of Medicine project team and its partners managed to develop a software tool that presents a valuable contribution to solving administrative problems of the medical schools in Croatia and is an example of successful implementation of IT technology in medical school management (2). Due to its reliance on omnipresent IT technology as well as to its applicability to different types of higher education institutions, we find their software solution highly relevant for the management of teaching processes not only in Croatia, but in a much wider educational context (3).

Conflict of interest: The author declares that she has no conflict of interest.

\section{References}

1. Sapunar D, Grković I, Lukšić D, Marušić M. Management of teaching processes using the Share point platform: A case study from the University of Split School of Medicine. Acta Med Acad. 2016;45(1):34-8.

2. Sapunar D, Grković I, Lukšić D, Marušić M. The business process management software for successful quality management and organization: A case study from the University of Split School of Medicine. Acta Med Acad. 2016;45(1):26-33.

3. Tariq M, Ali SA. Quality assurance and its application in medical education. J Coll Physicians Surg Pak. 2014;24(3):151-2. 